\title{
- Reconfiguração das práticas de edição de textualidades em ambiente digital a partir de mediações algorítmicas
}

\author{
Reconfiguration of textual editing practices in a digital \\ environment based on algorithmic mediations
}

\begin{abstract}
Luana Teixeira de Souza Cruz a,*
RESUMO: As dinâmicas de circulação de textos em ambiente digital são bastante alteradas pela mediação algorítmica e uso de plataformas. Esses algoritmos e plataformas detêm o poder simbólico de gatekeepers da sociedade contemporânea, definindo não somente quais informações devem circular, mas reconfigurando práticas e percepções coletivas. Este artigo traz um olhar sobre esse processo de reconfiguração com foco nas práticas incorporadas para edição e publicação de textos. Tem como objetivo fazer uma breve análise sobre um dos trabalhos de engenharia reversa (Gillespie, 2018) praticados por produtores de informação, que tentam deduzir os critérios dos algoritmos desde que ferramentas computacionais passaram a mediar meios de expressão e circulação de informação. Em especial, analisa como o uso do plugin Yoast S.E.O. para Wordpress interfere nas ações de editing com a promessa de assegurar visibilidade na instância publishing, mostrando que produtores de informação adotam para suas rotinas a "obediência” às lógicas de medição algorítmica.
\end{abstract}

Palavras-chave: Algoritmos; Edição; S.E.O.; Textualidades; Visibilidade.

ABSTRACT: The dynamics of text circulation in a digital environment are greatly altered by algorithmic mediation and the use of platforms. These platforms and algorithms hold the symbolic power of contemporary society's gatekeepers, defining not only what information should circulate, but reconfiguring collective practices and perceptions. This article takes a look at this reconfiguration process with a focus on embedded practices for editing and publishing texts. This article make a brief analysis on one of the reverse engineering works (Gillespie, 2018) practiced by information producers, who try to deduce the criteria of the algorithms since computational tools started to mediate the circulation of information. In particular, it analyzes how the use of the Yoast S.E.O. plugin for Wordpress interferes in the editing actions with the promise of ensuring visibility in the publishing instance, showing that information producers adopt "obedience" to the logic of algorithmic.

Keywords: Algorithms; Editing; S.E.O.; Textualities; Visibility.

a Programa de Pós-Graduação em Estudos de Linguagens, Centro Federal de Educação Tecnológica de Minas Gerais, Belo Horizonte, MG, Brasil.

*Correspondência para/Correspondence to: Luana Teixeira de Souza Cruz. E-mail: luanatsc@gmail.com.

Recebido em/Received: 13/04/2021; Aprovado em/Approved: 11/06/2021.

Artigo publicado em acesso aberto sob licença CC BY 4.0 Internacional ()우 


\section{INTRODUÇÃO}

A informação é um bem social valioso e o acesso universal a ela, um direito humano fundamental. As pessoas querem consumir informação, mas não querem e nem devem pagar por ela, conforme apontam as discussões sobre modelo de negócio do jornalismo em Cruz (2016) em diálogo com Costa (2014), Canavilhas (2005), Alves e Mendonça (2013). É demonstrada a exiguidade dos modelos adotados para viabilidade e existência lucrativa dos negócios ancorados na circulação de informação. Durante muitos anos, esse não foi um grande problema para as corporações midiáticas que produzem as textualidades ${ }^{1}$ carreadoras de informação, porque o negócio delas nunca foi vender informação, mas sim leiloar espaços publicitários para mostração das marcas. No entanto, as dinâmicas de circulação de textos na internet - mediadas por algoritmos e plataformas - subverteram as lógicas comerciais e levaram as marcas a investir menos na compra de espaços publicitários e mais na criação de locais próprios de mostração.

A partir daí, uma grande ruptura aconteceu. Enquanto as corporações midiáticas se debruçavam no dilema que implode seu modelo de negócio, grandes provedores de informação, mais especificamente o grupo que compõe as Big Five (Amazon, Google, Facebook, Microsoft, Apple), recriaram lógicas de circulação de textualidades ancoradas no engajamento das pessoas e passaram a protagonizar o regime capitalista contemporâneo. Essas empresas foram capazes de ditar o funcionamento de vários mercados, como do jornalismo, da música, do livro e do transporte (D'ANDREA, 2020). Por meio de suas plataformas (Twitter, Instagram, Facebook, Google Search, Amazon Search, Youtube, etc), os provedores de informação² atuam fortemente para reorganizar as relações interpessoais, o consumo de bens culturais, as discussões políticas, as práticas urbanas, entre outros setores. Portanto, detêm o poder simbólico de gatekeepers da sociedade contemporânea. Definem não somente quais informações devem circular, mas reconfiguram práticas e percepções coletivas.

\footnotetext{
${ }^{1}$ A ideia de textualidades aqui serve para ampliar a noção de texto, saindo de uma visão verbocêntrica e pensando em qualquer unidade de informação que constrói sentido a uma audiência. Sendo assim, fotografia, vídeo e gráficos, entre outros, são considerados textos. É uma noção construída a partir de das perspectivas de Ribeiro (2016) e Leal (2018).

${ }^{2}$ A noção de provedores da informação versus produtores de informação será usada neste artigo para diferenciar as duas instâncias de "trabalho" com conteúdos definidas por Gillespie (2018). Os provedores, representados por grandes empresas de tecnologia, mantêm seus algoritmos como segredos comerciais e estão, claramente, numa posição privilegiada para reescrever o entendimento de produção e circulação de conteúdo. Os produtores são todos aqueles que se orientam perante esses algoritmos.
} 
Diante disso, em que medida produtores de informação adotam e "obedecem" às lógicas de mediação impostas por algoritmos para alcançar visibilidade no ambiente digital? Este artigo traz um olhar sobre esse processo de reconfiguração com foco nas práticas incorporadas para edição e publicação de textos na plataforma Wordpress. Tem como objetivo fazer uma breve análise sobre um dos trabalhos de engenharia reversa (Gillespie, 2018) praticados por produtores de informação, que tentam deduzir os critérios dos algoritmos desde que ferramentas computacionais passaram a mediar meios de expressão e circulação de informação. Essa dedução, neste artigo exemplificada nos trabalhos de S.E.O. On Page ${ }^{3}$, é um movimento que prova o quanto a humanidade sujeitou os discursos e o conhecimento humano a lógicas procedimentais sustentadas pela computação.

O ambiente digital é dotado de dinamismo, não-linearidade, interconectividade, instantaneidade, imprevisibilidade, portanto, se faz um espaço complexo de circulação de textualidades. Nele, toda produção textual fica sujeita a uma cíclica experimentação e uma eterna versão beta, agenciada por uma linguagem guarda-chuva, a hipermídia. Santaella (2001) contribui com a ideia de complexidade quando conceitua hipermídia como uma linguagem em busca de si. Ela afirma que na hipermídia coexistem múltiplas linguagens e acessos de múltiplas telas. Para a autora, a linguagem hipermidiática introduziu grande hibridização com seus processos de comunicação interativos e dialógicos, o que contribui para que o ambiente digital se configure como um sistema complexo. É possível também enxergar a hipermídia como meio e isso corrobora a ideia de complexidade.

\footnotetext{
Os processos comunicativos devem pressupor tanto as diferentes linguagens e sistemas sígnicos que se configuram dentro dos veículos em consonância com o potencial e limites de cada veículo, quanto deve pressupor as misturas entre linguagens que se realizam nos veículos híbridos como a televisão e a hipermídia" (SANTAELLA, 2001, p. 380)
}

Contando a história de uma perspectiva dos produtores de informação, no início da vivência da cultura digital, a linguagem verbal escrita triunfou. Isso porque o hipertexto digital trouxe potencial à leitura não-linear e conexões conceituais que haviam sido ensaiadas de modo tímido em impressos. Logo depois, a imagem, que nos impressos cumpria "função subsidiária de ilustradora de ideias" (SANTAELLA, 2001, p. 392) apareceu em grande potência na hipermídia: com movimento e perspectiva. Em um terceiro momento, a escrita verbal retoma o protagonismo, porém, mais editada aos moldes da visibilidade e encontrabilidade, ou seja, adaptada à lógica algorítmica. Neste artigo será possível exemplificar essa dinâmica com estudo específico das práticas incorporadas à publicação e edição de textos na plataforma Wordpress.

Em todos esses momentos, ferramentas e modos de fazer textos foram criados para atender às necessidades produtivas. Mais importante que isso, as linguagens

\footnotetext{
${ }^{3}$ Ações que promovem a otimização de textos e páginas na internet para alcançar visibilidade aos algoritmos de motores de busca
} 
protagonistas condicionaram o pensamento de produtores e dos consumidores de informação. Da perspectiva dos provedores, tudo foi sempre uma reunião de dados massivos a serem trabalhados para melhorar experiências dos usuários atendendo aos interesses corporativos, que fizeram dessas empresas os grandes conglomerados de informação deste início do século XXI. Os provedores planejaram a construção de uma lógica de conhecimento a partir da avaliação algorítmica da informação.

\section{GATEKEEPERS EM AÇÃO}

Algoritmos e plataformas acabam por "dividir" espaços com gatekeepers tradicionais, como jornalistas, escritores e editores no processo de seleção de informações que circulam em ambiente digital. O conceito de gatekeeper é emprestado da Teoria da Comunicação, mas tratado de forma mais atualizada e contextualizada. A teoria do gatekeeper (Traquina, 2012) pode ser compreendida como uma série de escolhas em que o fluxo de informações tem de passar por gates, isto é, portões. Eles se configuram como áreas de decisão em relação às quais o gatekeeper (jornalistas e outros) tem que definir a relevância de uma informação ou não. Atualmente, há mais agentes envolvidos nesta decisão, inclusive softwares regidos por inteligência artificial. Ademais, é preciso cautela ao tratar da ideia de relevância, já que a mesma está imbricada de não neutralidade e de carga política, conforme será abordado neste artigo.

Quando se reflete sobre processos de seleção da informação, em especial pensando no trabalho do editor ${ }^{4}$, percebe-se que este profissional "atua ora como um gatekeeper passivo, ora como modelador ativo das forças culturais" (LANE, 1975, citado por MUNIZ JR., 2019, p. 2). Os processos de seleção da informação - automatizados por softwares ou feitos por atividade individual humana - implicam em "difusão de visões de mundo, estilos, formas e conteúdos de pensamento e posicionamento etc". (MUNIZ JR., 2019, p. 1). São atividades não neutras, dotadas de subjetividades e que ajudam a reconfigurar agendas sociais.

A atividade editorial trata, então, de dar forma material aos textos e de fazer circular conteúdos provenientes de espaços sociais com os quais mantém uma relação de forte interdependência e que, por isso, o habitam. Pensar a configuração contemporânea de espaços de produção de saberes como a ciência, a literatura, a educação, dentre outros, implica pensar os mecanismos institucionais por meio dos quais tais espaços logram espraiar, dentro de si e para

\footnotetext{
${ }^{4}$ Aqui uma referência não só a editores de livros ou revistas, mas editores de conteúdos de informação de modo geral. Inspira-se em Muniz Jr. (2020. p. 69) que, ao argumentar sobre a realidade do editor, trata da edição de "texto, de arte, de imagem, de vídeo, de som etc., porque todas essas materialidades, e as infinitas combinações entre elas, são editáveis".
} 
além de si, as ideias e os debates intelectuais que lhes concernem (MUNIZ JR., 2019, p. 2).

É perceptível, no entanto, que as empresas provedoras de informação dominaram expressivamente a seleção e circulação de informações, obrigando, inclusive, os editores a adotarem novas práticas de trabalho para alcançar visibilidade. Produtores de textos estão tensionados a conhecer sobre softwares, especialmente aqueles produtores sujeitos a mecanismos de busca, plataformas de mídia social, sistemas de recomendação e bases de dados. De todas as especificidades do ambiente digital, a introdução dos algoritmos nas práticas do conhecimento humano é a que mais complexifica a circulação de textualidades porque tem ramificações políticas (GILLESPIE, 2018).

Tal complexidade recai sobre os processos de edição de textualidades nas duas instâncias definidas por Muniz Jr. (2020) como editing e publishing. A primeira perspectiva - editing - diz respeito à noção de "momentos editoriais" (BECKER, 2008 citado por MUNIZ JR., 2020, p. 70), ou seja, ocasiões nas quais decisões-chave são tomadas na produção de uma textualidade. A segunda instância - publishing - tem como referência Pierre Bourdieu e suas reflexões sobre campo, legitimação, redes de sociabilidade e seus impactos na circulação de uma textualidade. Ambas as instâncias estão hoje muito alteradas pela mediação algorítmica, seja nos procedimentos relacionados ao editing, como retextualização, paratextualização, checagem, tradução, diagramação, mixagem, revisão, decupagem e finalização ou no conjunto de práticas de publishing, destinadas a preparar materiais simbólicos para circular publicamente (MUNIZ JR., 2020).

\section{A NÃO NEUTRALIDADE E AS CONFIGURAÇÕES DE ESPAÇOS SOCIAIS}

Os algoritmos impõem padrões de escolha de informação que variam desde as previsões que esses softwares conseguem fazer sobre os usuários até a produção de públicos calculados que geram as bolhas. Os provedores, por sua vez, apresentam as soluções como progressos. "No decorrer do século XIX, quando a burguesia consolidou sua posição de poder, o conceito de progresso foi perdendo cada vez mais as funções críticas que originalmente possuía" (BENJAMIN, 2006, p. 518). Os provedores tentam convencer de que é um benefício ter programas trabalhando na seleção de dados e produção de conhecimento coletivo, numa visão positivista de que cada nova versão dos softwares é superior à anterior. É preciso revitalizar a criticidade sobre tais ações apresentadas como progressos. Quando se trata de experimentos tecnológicos dos provedores de informação, certamente, a preocupação é maior com o funcionamento que os mantém detentores de poder (político e econômico) do que com o conhecimento coletivo.

Gillespie (2018) caracteriza as seis dimensões dos algoritmos de relevância pública que têm valor político, ou seja, que cumprem o papel de controle da realidade. A compreensão de duas dessas dimensões, em especial, é fundamental. A primeira delas diz respeito à não neutralidade algorítmica (principalmente quanto aos critérios de 
seleção da informação, que são ocultos). A segunda, que é foco deste artigo, envolve o entrelaçamento das práticas profissionais dos produtores de informação para se adaptar à lógica dos softwares. Esses produtores, muitas vezes, não se questionam sobre as políticas dos algoritmos.

"Vivemos numa sociedade na qual a tecnologia é apresentada como algo neutro (...) e como algo positivo (na medida em que acena com a possibilidade de uma vida melhor)" (CUPANI, 2011, p. 168). Na verdade, porém, a tecnologia não é isenta, imparcial ou objetiva, pelo contrário, está coberta de ideologias e expressões de poder. Os algoritmos e as plataformas são a própria representação dessa tecnologia criada por grupos sociais hegemônicos e, embora sejam apresentados em caixas-pretas, são manejados com intencionalidades políticas e econômicas. Isso dificulta movimentos de contrafluxo ou ressignificações da produção que se sobreponham à lógica algorítmica.

A promessa de objetividade algorítmica é comparável ao mito da imparcialidade jornalística, conforme argumenta Gillespie (2018). É uma neutralidade ideal, portanto inalcançável e inexistente no universo prático da produção da informação. Os jornalistas até tentam manter esse ritual da objetividade para legitimar suas ações, no entanto, a neutralidade se sustenta somente no discurso.

Assim como os motores de busca, os jornalistas desenvolveram táticas para determinar o que é mais relevante, como reportá-lo e como garantir sua relevância um conjunto de práticas que são relativamente invisíveis para sua audiência; uma meta que eles admitem ser mais difícil de seguir do que parece; e um princípio que ajuda a deixar julgamentos de valor e políticas pessoais de lado, mas não os elimina. (GILLESPIE, 2018, p. 108)

\footnotetext{
Assim ocorre com os algoritmos, que apresentam um propósito de servir à sociedade com seleção de informações, como se fossem intervenções estritamente técnicas, mas são carregados de vieses e automatizações equivocadas. Manter aparência de tecnicidade ajuda os provedores a fugir de acusações de manipulação de resultados. Imperdoável é ignorar que os algoritmos são programados por seres humanos, com suas escolhas subjetivas ou guiadas por instituições (GILLESPIE, 2018).
}

Provedores de informação têm moldado espaços sociais (BOURDIEU, 1996) e espaços de expressão (MUNIZ Jr., 2019) porque são hoje instituições munidas de grande capital econômico e cultural. Tornaram-se agentes unificadores das textualidades carreadoras de informação e reproduzem habitus de mediadores tradicionais (gatekeepers do século XX, como jornalistas e editores). Assim, os provedores de informação influem na vida social (sobretudo espaços de exercício do poder) evidenciando certas textualidades em detrimento de outras, com práticas diferenciadoras e distintivas (BOURDIEU, 1996). Portanto, transformam o padrão das mediações online em arquiteturas privadas e negócios bem lucrativos.

Não é uma mediação qualquer, é algo tão complexo e invisível aos leigos que não permite a regulação dessas corporações como grupos de mídia. Elas se apresentam 
como empresas de tecnologia, sob a máscara da neutralidade técnica. Ademais, materializam suas ações em alguns pilares (D'ANDREA, 2020) dentro das plataformas: a) programabilidade, em que códigos, algoritmos e rotinas computacionais ditam práticas de uso; b) popularidade, em que sistemas de ranqueamento e reconhecimento social (economia de likes) dão vazão a informações mais "competitivas" nesses parâmetros; c) conectividade e datificação, em que a coleta de rastros deixados pelas pessoas em ambiente digital permite personalização segmentada da informação e ciclos preditivos de comportamento de consumidores, tudo isso justificado por uma ciência de dados.

É assim que as plataformas impõem lógicas mercadológicas em atividades cotidianas e estratégicas como publicação de textos, imagens, consumo de filmes, mobilidade urbana, turismo, entre tantas outras. A ideia de plataformização da sociedade e da vida firma-se cada vez mais, a partir do momento em que as ações desses intermediários ficam naturalizadas. Tal contexto corrobora a afirmação de Sandel (2016) sobre sermos uma sociedade de mercado com "um modo de vida em que os valores de mercado permeiam cada aspecto da atividade humana. É um lugar em que as relações sociais são reformatadas à imagem do mercado" (SANDEL, 2016, p. 16). As plataformas são um reflexo do que Sandel denomina sociedade do mercado "em que quase tudo pode ser comprado e vendido" (SANDEL, 2016, p. 11). Para o autor, nas três últimas décadas, os mercados passaram a governar nossa vida como nunca e não chegamos a essa situação por escolha deliberada. "É quase como se a coisa tivesse se abatido sobre nós" (SANDEL, 2016, p. 11).

Os grandes provedores testam os limites éticos do mercado quando protagonizam uma injusta troca de informações, escancarada pelo documentário Dilema das Redes5. Se você não paga por um produto, provavelmente você é o produto. Essa é exatamente a lógica de mercado das plataformas, que coletam dados de seus usuários para, entre outras ações, direcionar publicidade, conteúdo e informação com vistas a influenciar opiniões, construir visões e até mesmo recriar noções do que é amizade, racismo e política. "Os algoritmos também afetam a maneira que as pessoas procuram informações, como elas percebem e pensam sobre os horizontes de conhecimento, e como elas se compreendem no e pelo discurso público" (Gillespie, 2018, p. 110)

As plataformas promovem, também, a lógica "fura fila" exposta por Sandel (2016) com ofertas de versões premium, prime ou pro. Nesses casos, além de você ser o produto, fornecendo dados essenciais, ainda paga por uma "área vip".

No auge da Web 2.0, propagou-se a ideia de que os serviços online seriam fundamentalmente "gratuitos". Hoje, a adoção das plataformas como padrão para práticas diversas como ouvir música e podcasts (Spotify), armazenar arquivos (Dropbox) ou ler artigos

\footnotetext{
${ }_{5}^{5}$ Documentário dirigido por Jeff Orlowski e escrito por Orlowski, Davis Coombe e Vickie Curtis. Foi lançado pela Netflix, em 9 de setembro de 2020 e analisa o papel das plataformas de redes sociais na sociedade.
} 
jornalísticos ou de opinião (Medium) leva cada vez mais pessoas a pagar alguns dólares mensais para ter acesso pleno a serviços. Isso é ainda mais efetivo na indústria audiovisual, resultando, por parte das plataformas, na adesão ao modelo de assinaturas (por exemplo, o YouTube Red, posteriormente rebatizado como YouTube Premium) e em um forte investimento em produções próprias (YouTube Originals). (D'ANDREA, 2010, p. 29)

A ideia que se tinha, entre os anos 2000 e 2010, de uma internet promotora da cultura da participação, que poderia democratizar o acesso à informação, começa a ser frustrada quando desvelamos o império construído pelas Big Five. O processo de plataformização se deu perante promessa das empresas provedoras de informação (detentoras das plataformas) de que se configuraria a descentralização e a recuperação de dados para construção de conhecimento coletivo. Na primeira promessa, plataformas cederiam estrutura tecnológica para as pessoas se conectarem, ampliarem seus acessos e se comunicarem com mais facilidade. $\mathrm{Na}$ segunda promessa, dariam condições para reunir todos os históricos de interações a fim de proporcionar entendimentos globais que poderiam sugerir inteligência coletiva. No entanto, o que aconteceu foi uma apropriação, por parte desses provedores, de dados externos para seus próprios bancos de dados, traço fundamental para o sucesso de seu modelo econômico.

(...) as plataformas se apropriam das lógicas de conexão e as potencializam como parte de uma estratégia - comercial, sobretudo - que visa incentivar usuários a deixar rastros de suas relações, preferências, etc. Considerando essa concepção, parece-nos que é grande o risco de, ao usarmos automaticamente o termo rede social, enfatizarmos apenas a dimensão relacional das plataformas, invizibilizando os aspectos materiais, econômicos, políticos, etc da conectividade online. (D'ANDRÉA, 2020, p. 15).

A dinâmica "encaixapretada" (LATOUR 1987, PINCH; BIJKER, 1984, citados por Gillespie, 2018, p. 106) dos algoritmos na escolha do que é relevante acaba por criar lógicas excludentes, as mesmas argumentadas por Deleuze:

No capitalismo só uma coisa é universal, o mercado. Não existe Estado universal, justamente porque existe um mercado universal cujas sedes são os Estados e as Bolsas. Ora, ele não é universalizante, homogeneizante, é uma fantástica fabricação de riqueza e de miséria. Os direitos do homem não nos obrigarão a abençoar as 'alegrias' do capitalismo liberal do qual eles participam ativamente. Não há Estado democrático que não esteja totalmente comprometido nesta fabricação da miséria humana. A vergonha é não termos nenhum meio seguro para preservar, e principalmente para alcançar os devires, inclusive em nós mesmos. (DELEUZE, 1992, p. 213)

Nas plataformas, informações como idade, localização, hábitos, preferências e frequências de uso são cruzadas com o intuito de traçar perfis segmentados ou de 
prever comportamentos de públicos, o que Gillespie (2018) chama de produção de públicos calculados. D’Andrea alerta para “o modo como as plataformas, mais do que revelar, constituem novos públicos a partir dos dados que priorizam e das preferências do mercado" (D'ANDREA, 2020, p. 32). Sendo assim, acabam por reforçar homogeneizações e visões preconceituosas. Um exemplo desses desdobramentos excludentes é o racismo algorítmico.

\begin{abstract}
Com frequência, estes mecanismos de segmentação dão margem para o direcionamento de anúncios com viés claramente racista ou xenófobo. Em 2017, reportagem do site ProPublica revelou que o Facebook oferecia, como possibilidade de segmentação de público, categorias antissemitas como "Jew Hater" e "How to burn jews" ("odiador de judeus" e "como queimar judeus", em uma tradução livre para o português). [...] Já o BuzzFeed descobriu que a Google permitia a associação de anúncios a expressões racistas como "black people ruin neighborhoods." (em uma tradução livre "negros arruinam vizinhanças"). [...] Após as denúncias, as plataformas afirmaram que ajustes foram feitos em seus sistemas. (D'ANDREA, 2020, p. 32)
\end{abstract}

Em novembro de 2020, durante edição virtual da Feira Preta, principal evento de empreendedorismo negro do Brasil, o tema do racismo algorítmico foi discutido a partir de uma perspectiva propositiva. Uma das mais influentes mulheres no mundo da tecnologia, a empresária senegalesa Mariéme Jamme, disse:

Trabalhar em empresas é bom, ser ativista de tecnologia também é bom, mas a gente precisa sentar e construir. Precisamos ser o próximo Mark Zuckerberg. Nós não temos muita história de gente preta construindo, não é? A gente precisa construir as soluções. Sentar, programar, desenvolver um aplicativo e jogar no mercado ${ }^{6}$.

A fala de Mariéme Jamme reforça a ideia de não neutralidade dos algoritmos e plataformas, sendo necessária diversidade na construção desses mecanismos para que lógicas homogeneizantes não se repitam. Assim como é necessária diversidade em todas as instâncias definidoras em espaços sociais (BOURDIEU, 1996) e espaços de expressão (MUNIZ Jr., 2019): empresas de tecnologia, editoras, jornais, indústria cinematográfica, indústria musical, centros de pesquisa e ciência, etc...

\title{
PRÁTICAS INCORPORADAS
}

Entre 2013 e 2014, quando Cruz (2014) pesquisou o processo de produção de repórteres de um jornal mineiro que incorporava práticas de análises de resultado em audiência e

6 Disponível em https://www.uol.com.br/ecoa/ultimas-noticias/2020/11/25/mariemejamme-a-mulheres-negras-precisamos-ser-o-proximo-mark-

zuckerberg.htm\%E2\%9D\%A4\%EF\%B8\%8F. Acesso em 30 de mar 2021. 
gerenciamento de tags ao trabalho jornalístico, denominou algumas dessas habilidades de técnicas de folksonomia e hierarquia reversas. Naqueles casos analisados, já havia uma consciência mínima de critérios algorítmicos que davam visibilidade ou não a conteúdos no ambiente digital, mas os efeitos políticos dos softwares não chegaram a ser problematizados. Os trabalhos nesse sentido amadureceram, apesar de pesquisadores (tanto quanto os produtores de informações) terem pouco acesso ao universo "encaixapretado" dos algoritmos. Os cientistas têm se dedicado mais frequentemente a revelar as consequências sociais de ter os programas como mediadores do conhecimento coletivo.

Para Gillespie, "a maioria dos usuários não se debruça sobre os critérios algorítmicos e tende a tratá-los como ferramentas não problemáticas a serviço de uma atividade maior: encontrar uma resposta, resolver um problema, entreter" (GILLESPIE, 2018, p. 106). Apenas entrelaçar as lógicas computacionais às práticas de produção da informação demonstra falta de compreensão do quanto o mundo é alterado por essas entregas dos provedores, que são instrumentos de (grandes) negócios. Quando o produtor luta para vencer o incompreensível algoritmo, sem questioná-lo politicamente, poderá alcançar a visibilidade online, mas nunca compreenderá seu trabalho como contrafluxo de poder.

São inúmeras as situações de uso do ambiente digital que demonstram habilidades em deduzir o funcionamento de algoritmos: profissionais de S.E.O. (Search Engine Optimization, em inglês) e os spammers que praticam testes e engenharia reversa; produtores de conteúdo que se orientam pela otimização de mecanismos de busca e criam modos especiais de edição de suas textualidades; usuários que operam hashtags para se juntar a conversas online, mas que, na verdade, entram para um hall de informação selecionada por algoritmos; pesquisadores que criam métodos de observação em plataformas para colher resultados com menor impacto algorítmico, entre outros. No entanto, nenhuma dessas inciativas é suficiente para desfazer a forma de poder dos algoritmos, pelo contrário, impulsionam atualizações. Estas, por sua vez, são apresentadas pelos provedores como progresso em uma visão que serve ao “determinismo tecnológico simplista” (GILLESPIE, 2008, p. 98).

Uma dessas técnicas em especial, o S.E.O. On Page, é responsável pelo tratamento e otimização de textualidades para que se tornem potencialmente mais visíveis no ambiente digital. Essa visibilidade é mediada por algoritmos que definem critérios de relevância, auxiliando o produtor de informação a editar as textualidades para serem vistas, selecionadas e distribuídas aos consumidores.

O principal objetivo das técnicas de S.E.O. On Page é tornar o conteúdo mais interessante aos algoritmos de indexação dos motores de busca, como Google e Bing. Entre as técnicas voltadas para produção textual estão processos de edição de títulos, reconfiguração de parágrafos e escolha de palavras-chave. Editores, redatores e escritores incorporam em seus processos criativos uma ideia além da pauta: o que 0 meu leitor buscaria no Google para encontrar o conteúdo sobre o qual estou 
produzindo? E, assim, trabalham equilibrando processo criativo, demandas de públicos e "obediência" aos algoritmos responsáveis pela visibilidade online.

Os profissionais também monitoram métricas em tempo real, por meio de ferramentas de web analytics, em que é possível medir desempenho e performance de conteúdos, e se envolvem na produção de títulos testáveis (BUENO; REINO, 2019), ou seja, usam recursos de atração de cliques por meio dos títulos. É possível apontar "eficiência" do título no que diz respeito à audiência na seguinte lógica: quando cliques do público engrossam as estatísticas, o produtor analisa a partir de quais palavras-chaves a audiência está acessando aquele conteúdo e, assim, cria uma engenharia reversa de usos de tags e outras estratégias cuja função é atrair audiência.

Não compreender algoritmos de motores de busca, negar a necessidade de aplicação de técnicas de otimização e estar fora do jogo das plataformas pode custar a produtores de informação a invisibilidade que, certamente, implode suas atividades fins e seus modelos de negócio. Trata-se aqui de discutir processos de produção e edição profissionais que precisam de retorno em audiência, não incluindo neste ciclo do desempenho os projetos que podem sobreviver sem, necessariamente, se aplicar a este jogo.

\footnotetext{
Se os usuários falharem ou se recusarem a se encaixar nas suas práticas e a conceder significado a elas, o algoritmo irá falhar. Isso significa que não devemos considerar seus "efeitos" nas pessoas, mas um "entrelaçamento" multidimensional entre algoritmos postos em prática e as táticas dos usuários que fazem face a eles. (GILLESPIE, 2018, p. 110)
}

A seguir será explorado um tipo de entrelaçamento com a prática para plataforma Wordpress no qual ficam exemplificadas situações em que produtores de informação se adequam aos algoritmos dos quais dependem.

\section{Yoast S.E.O. para Wordpress}

Para permitir um olhar sobre esse processo de reconfiguração com foco nas práticas incorporadas para edição e publicação de textos na plataforma Wordpress, optou-se por uma análise qualitativa por meio da observação de como opera a ferramenta Yoast S.E.O. As informações foram obtidas a partir de ambiente de administração e publicação de textos usados para fins de ensino e aprendizagem em cursos de graduação e pós-graduação7. O procedimento simulou a publicação de um texto com o objetivo de capturar as funcionalidades do Yoast S.E.O e ajudar nas reflexões de como produtores de informação "obedecem" às lógicas de mediação impostas por algoritmos para alcançar visibilidade.

O Wordpress é uma plataforma que se sustenta na lógica da programabilidade, popularidade, conectividade e datificação. É um software de código aberto para

\footnotetext{
7 Site: http://producaoegestaodeconteudo.com/. Acesso em 8 junho 2021.
} 
publicação de textualidades. Foi projetado para atender, em configuração mínima, a leigos que não sabem criar e manter uma página na Web. No entanto, oferece recursos para quem detém conhecimento profissionalizado de web desenvolvimento. $O$ Wordpress surgiu em 2003 e, atualmente, é a plataforma escolhida por aproximadamente $40 \%$ de todos os sites da internet, segundo dados da própria empresa ${ }^{8}$.

Já o Yoast S.E.O. é um plugin ${ }^{9}$ que pode ser adicionado ao Wordpress e que auxilia na configuração de parâmetros de otimização em cada post publicado (S.E.O. On Page). A parametrização é individualizada em cada textualidade que se edita. O Yoast S.E.O. surgiu em 2007, mas, em 2012, foi atualizado para uma versão mais próxima da que se oferece hoje. A empresa Yoast (SEO for everyone) foi criada em 2010, entrando para o grupo de empresas de tecnologia que em seu discurso apoia o código aberto e a liberdade do usuário em incorporar aprendizados às praticas de publicação de conteúdo online.

A configuração de parâmetros S.E.O., por meio do plugin Yoast, pode ser feita durante a produção e edição da textualidade. A ferramenta vai pontuando as ações do editor no sentido de atender às demandas de visibilidade - e apresentando o resultado da análise.

Figura 1. Análise Yoast S.E.O.

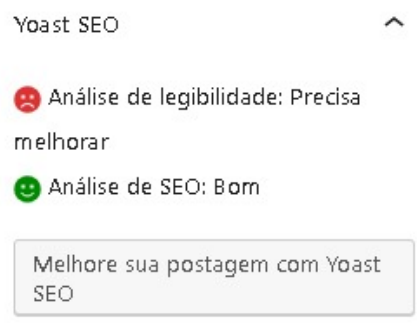

Fonte: https://producaoegestaodeconteudo.com/wp-admin/.

A ideia é guiar o editor para que ele não precise trabalhar intuitivamente na organização e hierarquização textual, na seleção de palavras-chaves, na divisão de parágrafos, na construção de links internos e externos, na legibilidade ${ }^{10}$, entre outros processos de edição. Todos esses itens são importantes marcadores para algoritmos de motores de busca durante o rastreamento, a indexação e o ranqueamento de

${ }^{8}$ Disponível em https://wordpress.org/about/. Acesso em 30 de mar 2021.

9 É uma extensão modular que pode ser adicionada a softwares para acrescentar funções e facilidades.

10 Parâmetro conhecido também como escaneabilidade, considerado por especialistas em S.E.O. como uma formatação textual que promove o "passar de olhos" do leitor, sendo que o público poderá captar essências do conteúdo sem a leitura completa. Geralmente, a ferramenta Yoast S.E.O. sugere a divisão do texto em pequenos blocos e separados por intertítulos, formato que é mais legível também aos algoritmos de motores de busca. 
conteúdos no ambiente digital. O Google, por exemplo, trabalha com algoritmos rastreadores que examinam sites automaticamente seguindo URL's que geralmente são construídas pela exata combinação de palavras que estão no título de um conteúdo. O principal rastreador, chamado Googlebot ${ }^{11}$, vai de link em link e leva dados sobre essas páginas para os servidores do Google.

O benefício oferecido pelo Yoast S.E.O. é entregar ao produtor de informação sinais de que o texto em criação está "agradando" ou não aos rastreadores. Com a textualidade inserida no rascunho do Wordpress, o plugin aponta os bons resultados alcançados e os pontos a melhorar no texto sob a perspectiva da visibilidade algorítmica. Parte desses parâmetros se baseia na palavra-chave (ou frase-chave) escolhida pelo autor do texto como a operadora do processo de atração - tanto de leitores quanto de relevância pelos algoritmos.

Em vermelho aparecem os parâmetros que ainda precisam ser melhorados. Ao solicitar a inserção de links internos, a ideia é criar autorreferências do site que indicam autoridade na produção de informação, fator ${ }^{12}$ considerado pelos motores de busca no ranqueamento. Ao sugerir o uso da frase-chave na introdução, a intenção é auxiliar na identificação temática feita pelos algoritmos nos textos, seguindo uma ordem de leitura que, geralmente privilegia título, subtítulo, primeiro parágrafo e intertítulos. 0 parâmetro de densidade da frase-chave indica a necessidade de repetição da operadora de atração, de forma a marcar para os algoritmos a importância deste termo na produção textual como todo.

Já os parâmetros marcados em verde pelo Yoast S.E.O indicam que a padronização está satisfatória. No exemplo da Figura 2, considerou-se suficiente o tamanho do título e do texto, os links de saída - que apontam para outros sites e também servem na construção de autoridade - além do atributo alt da imagem. Este, em especial, diz respeito ao descritivo de imagens inseridas no texto que precisa ser feito em um campo específico da plataforma Wordpress e ajuda na encontrabilidade de uma textualidade. Isso porque o texto verbal poderá ser encontrado por meio da indexação da imagem que o acompanha - como é possível ver quando se promove uma busca na ferramenta Google Imagens ${ }^{13}$. Nesse caso, uma foto, ilustração ou gráfico pode servir como agente atrator para o conteúdo.

\footnotetext{
${ }^{11}$ Disponível em https://www.google.com/intl/pt-

BR/search/howsearchworks/algorithms/. Acesso em 30 de mar 2021.

${ }^{12} \mathrm{O}$ Google considera entre 150 e 200 fatores para ranqueamento de sites na página de busca. A prioridade desses fatores é alterada frequentemente pelo motor de busca, dificultando o acompanhamento dessas regras por produtores de informação. Disponível em: https://rockcontent.com/br/blog/fatores-de-rankeamento-do-google/. Acesso em 8 junho 2021. ${ }^{13}$ Disponível em: https://www.google.com/imghp?hl=pt-br. Acesso em 8 junho 2021.
} 
Figura 2. Parâmetros apontados pelo Yoast S.E.O.

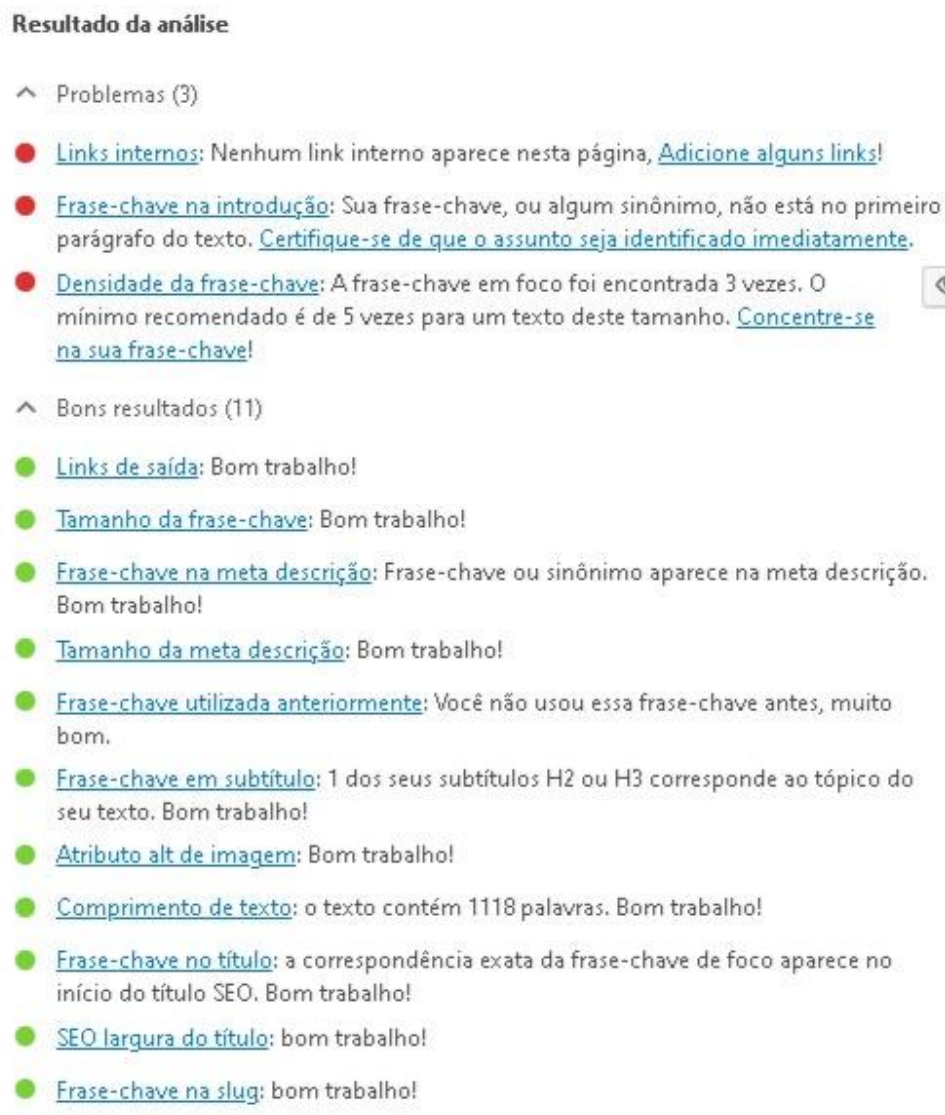

Fonte: https://producaoegestaodeconteudo.com/wp-admin/.

Enfim, o Yoast S.E.O. se coloca como "bússola editorial" e poderá sugerir alterações de tamanho do texto, escolhas semânticas (como mudar a frase-chave), uso de conectivos (conjunções, advérbios, pronomes), entre outras práticas. Sendo assim, interfere nas ações de editing com a promessa de assegurar visibilidade na instância de publishing.

Essa parametrização tem implicações estéticas e na construção de sentido da textualidade publicada. Além disso, cria uma homogeneização para apresentação de textos, que reduz a diversidade editorial no ambiente digital, considerando o expressivo número de sites que usam Wordpress como plataforma. Ademais, o texto é editado para atender a algoritmos gatekeepers e não necessariamente ao público leitor para o qual foi destinado. Talvez não atenda também aos códigos de ética e contratos sociais que regem relações entre produtores de informação e seus públicos, como no caso de conteúdos jornalísticos. Quando produtores usam este plugin e outros similares, as alterações de padrões textuais para otimização podem resultar em transgressões deontológicas. 


\section{CONCLUSÕES}

Usar a estratégia de S.E.O. On Page, assim como ferramentas que auxiliam na otimização da visibilidade - como plugins e outras técnicas - constitui atualmente uma prática mercadológica naturalizada. Mostra que produtores de informação adotam para suas rotinas a "obediência" às lógicas de mediação impostas por algoritmos para alcançar visibilidade no ambiente digital. As questões éticas decorrentes dessa constatação poderiam ser analisadas caso a caso: olhar para textos de marketing de conteúdo usando estratégias de otimização é diferente de observar o uso dessa técnica em conteúdos de divulgação cientifica, por exemplo. No primeiro caso, a textualidade atende ao objetivo de construção de argumentos de venda, o que justificaria o uso de engenharia reversa para performance. No segundo, cria-se uma polêmica enorme no que conceitualmente se entende como divulgação científica, em que, de forma ideal, a produção de conteúdo não deveria se pautar por métricas de desempenho digital. Muitos outros exemplos poderiam ser analisados, envolvendo inúmeros tipos de produção de informação, o que não é objetivo deste artigo. As sugestões feitas por plug-ins como Yoast S.E.O. podem levar o produtor a alterar completamente o estilo de escrita, a escolha de linguagem com implicações, inclusive, discursivas.

É compreensível que ferramentas e modos de fazer textos sejam reconfigurados para atender às necessidades produtivas, principalmente para produtores de informação que precisam obedecer às lógicas de audiência capitalista. Mas não se pode perder de vista a quantidade de camadas que são, atualmente, criadas na circulação textual: há algoritmos definidores de parâmetros de relevância, que motivam a criação de ferramentas (plugins e outros) que, por sua vez, ensinam ao humano produtor/editor como alcançar a parametrização. É este fluxo de produção/edição, sem precedentes na história da escrita e da leitura, que se destaca neste artigo. Tal modelo implica na vinculação dos produtores a uma agenda de informações e de visões de mundo que é definida pelos detentores desses algoritmos.

Demonstrou-se aqui apenas um método produtivo em ambiente digital, entre muitos, nos quais ocorre a reconfiguração de práticas de edição a partir de mediações algorítmicas. $\mathrm{O}$ uso do Yoast S.E.O. e as interferências dessa ferramenta no trabalho de edição entrelaçam modos humanos de pensar e organizar textualidades com hierarquias e lógicas de softwares. Os produtores tendem a naturalizar o uso de ferramentas como essa para que se encaixem em suas rotinas, além de acomodar em seus processos a crescente influência de tecnologias. São, na verdade, os provedores de informação que fazem parecer tão natural a plataformização das textualidades e a obediência aos parâmetros algorítmicos. Talvez por isso soa tão distópico pensar em um cenário de circulação desses conteúdos em ambiente digital sem plataformas. Aliás, como seria? 


\section{REFERÊNCIAS}

ALVES, I. F.; MENDONÇA, S. Modelos de negócio em tempos de tensão digital: Perspectivas de renovação no caso da imprensa. Publicações Obercom, Lisboa (PT), 2013.

BENJAMIN, Walter. Teoria do conhecimento, teoria do progresso. Em.: BENJAMIN, Walter. Passagens. Belo Horizonte: Editora UFMG; São Paulo: Imprensa Oficial do Estado de São Paulo, 2006. p.499-530.

BOURDIEU, Pierre. Espaço social e espaço simbólico. Em: Razões práticas: sobre a teoria da ação. Trad. Mariza Corrêa. Campinas - SP: Papirus, 1996. p.13-34.

BUENO, Thaisa; REINO, Lucas Santiago Arraes. SEO no jornalismo: títulos testáveis e suas implicações. Estudos em Jornalismo e Mídia [em linha]. 2019, v. 16, n. 2, p. 98-112. [Acesso em 30 março 2021]. DOI 10.5007/1984-6924.2019v16n2p98. Disponível em: https://doi.org/10.5007/1984-6924.2019v16n2p98

CANAVILHAS, João Manuel Messias. Retrato dos jornalistas online em Portugal. Em: SOPCOM 2005: $4^{\circ}$ Congresso da Associação Portuguesa de Ciências da Comunicação. 2005. p. 1393-1402.

COSTA, Caio Túlio. Um modelo de negócio para o jornalismo digital. Columbia Journalism Review, a Revista de Jornalismo ESPM, n. 9, p. 51, 2014. [Acesso em 8 junho 2021].Disponível em:http://observatoriodaimprensa.com.br/imprensa-emquestao/um_modelo_de_negocio_para_o_jornalismo_digital/

CRUZ, L.T.S. Rota hipertextual baseada em tags: discussão de processos de produção e leitura como sistemas complexos no contexto da Web Semântica [em linha]. 2014. Dissertação (Mestrado em Estudo de Linguagens). Belo Horizonte, MG. Centro Federal de Educação Tecnológica de Minas Gerais (CEFET-MG).

CRUZ, L.T.S.. Ethos do jornalismo no século 21: modelo de negócio, profissão e gênero. TROPOS, v. 5, n. 1, 2016.

CUPANI, Alberto. Tecnologia e poder . Em.: CUPANI, Alberto. Filosofia da tecnologia: um convite. Florianópolis: Editora da UFSC, 2011. p. 151-168.

D'ANDRÉA, Carlos. Pesquisando plataformas online: conceitos e métodos. Salvador: EDUFBA, 2020. [Acesso em 8 junho 2021] Disponível em https://repositorio.ufba.br/ri/handle/ri/32043

DELEUZE, Gilles. Política. Em.: DELEUZE, Gilles. Conversações. São Paulo: Editora 34, 1992. p.207-226.

GILLESPIE, Tarleton. A relevância dos algoritmos. Parágrafo [em linha]. 2018, v. 6, n. 1, p. 95-121. [Acesso em 30 março 2021]. Disponível em: http://revistaseletronicas.fiamfaam.br/index.php/recicofi/article/view/722/563

LEAL, Bruno. Do texto à textualidade na comunicação: contornos de uma linha de investigação. Em: LEAL, B.; CARVALHO, C. A.; ALZAMORA, Geane. Textualidades Midiáticas. Belo Horizonte: PPGCom/UFMG, 2018. 172 p. [Acesso em 30 março 2021]. 
Disponível em: https://seloppgcom.fafich.ufmg.br/novo/publicacao/textualidadesmidiaticas/

MUNIZ Jr., José de Souza, 2019. O editor como (mediador) intelectual e o espaço editorial como ilusão de óptica: apontamentos teórico-metodológicos. Em: $42^{\circ}$ Congresso Brasileiro de Ciências da Comunicação [em linha]. Belém, PA, 2019. [Acesso em 31 março 2021]. Disponível em: https://portalintercom.org.br/anais/nacional2019/resumos/R14-0068-1.pdf.

MUNIZ Jr., José de Souza. Edição. Em: CABRAL, Cleber Araújo; RIBEIRO, Ana Elisa (Orgs). Tarefas da Edição. Belo Horizonte: DEDC, LED, Impressões de Minas, 2020. p. 68-76. [Acesso em 8 junho 2021]. Disponível em:

https://www.letras.bh.cefetmg.br/wp-content/uploads/sites/193/2019/10/Tarefas-daEdic\%cc\%a7a\%cc\%830-arquivo-digital-07-10-20.pdf

O DILEMA das Redes Sociais (Netflix, 2020). Direção Jeff Orlowski. Estados Unidos: Netflix, 2020.

RIBEIRO, Ana Elisa. Textos multimodais: leitura e produção. São Paulo: Parábola Editorial, 2016.

SANTAELLA, Lucia. Linguagens híbridas. Em.: SANTAELLA, Lucia. Matrizes da linguagem e pensamento. Sonora, visual, verbal. São Paulo: Editora lluminuras, 2001. p.369-388.

SANTOS, Cléberson, 2020. Mariéme Jamme a mulheres negras: "Precisamos ser o próximo Mark Zuckerberg". [em linha]. 26 novembro 2020. [Acesso em 30 março 2021]. Disponível em: https://www.uol.com.br/ecoa/ultimasnoticias/2020/11/25/marieme-jamme-a-mulheres-negras-precisamos-ser-o-proximomark-zuckerberg.htm\%E2\%9D\%A4\%EF\%B8\%8F

SANDEL, Michael J. O que o dinheiro não compra: os limites morais do mercado. Rio de Janeiro: Civilização Brasileira, 2016.

TRAQUINA, Nelson. Teorias do Jornalismo. Porque as notícias são como são. Vol. 1. Florianópolis: Insular, $3^{\text {a }}$ edição rev. 2012. 